\title{
The Applicability of Remote Sensing Models of Soil Salinization Based on Feature Space
}

\author{
Jing Liu ${ }^{1,2,3}$, Li Zhang ${ }^{1,2}$, Tong Dong ${ }^{1,2}{ }^{-}$, Juanle Wang ${ }^{3}{ }^{-}$, Yanmin Fan ${ }^{1,2, *}$, Hongqi Wu ${ }^{1,2, *}$, Qinglong Geng ${ }^{4}$, \\ Qiangjun Yang ${ }^{5}$ and Zhibin Zhang ${ }^{1,2}$
}

1 College of Resources and Environment, Xinjiang Agricultural University, Urumqi 830000, China; 320202511@xjau.edu.cn (J.L.); zhangli0628@163.com (L.Z.); mr_dongtong@126.com (T.D.); 320202525@xjau.edu.cn (Z.Z.)

2 Key Laboratory of Grassland Restoration and Environmental Information, Urumqi 830000, China

3 State Key Laboratory of Resources and Environmental Information System, Institute of Geographic Sciences and Natural Resources Research, Chinese Academy of Sciences, Beijing 100101, China; wangj@@igsnrr.ac.cn

4 Institute of Soil and Fertilizer and Agricultural Water Conservation, Xinjiang Academy of Agricultural Sciences, Urumqi 830000, China; qlgeng@foxmail.com

5 China Geo-Engineering Corporation, Beijing 100101, China; viperc@126.com

* Correspondence: ymfantt@126.com (Y.F.); hqwu7475@126.com (H.W.); Tel.: +86-136-0998-5664 (Y.F.);+86-139-9925-1674 (H.W.)

Citation: Liu, J.; Zhang, L.; Dong, T.; Wang, J.; Fan, Y.; Wu, H.; Geng, Q.;

Yang, Q.; Zhang, Z. The Applicability of Remote Sensing Models of Soil Salinization Based on Feature Space. Sustainability 2021, 13, 13711. https:// doi.org/10.3390/su132413711

Academic Editor:

Cristian-Valeriu Patriche

Received: 10 November 2021

Accepted: 8 December 2021

Published: 12 December 2021

Publisher's Note: MDPI stays neutral with regard to jurisdictional claims in published maps and institutional affiliations.

Copyright: (c) 2021 by the authors. Licensee MDPI, Basel, Switzerland. This article is an open access article distributed under the terms and conditions of the Creative Commons Attribution (CC BY) license (https:// creativecommons.org/licenses/by/ $4.0 /)$.

\begin{abstract}
Soil salinization is a major challenge for the sustainable use of land resources. An optimal remote sensing inversion model could monitor regional soil salinity across diverse geographical areas. In this study, the feature space method was used to study the applicability of the inversion model for typical salt-affected soils in China (Yanqi Basin (arid area) and Kenli County (coastal area)), and to obtain soil salinity grade distribution maps. The salinity index (SI) surface albedo (Albedo)model was the most accurate in both arid and coastal regions with overall accuracy reaching $93.3 \%$ and $88.8 \%$, respectively. The sensitivity factors for the inversion of salinity in both regions were the same, indicating that the SI-Albedo model is applicable for monitoring salinity in arid and coastal areas of China. We combined Landsat 8 Operational Land Imager image data and field data to obtain the distribution pattern of soil salinity using the SI-Albedo model and proposed corresponding countermeasures for soil salinity in the Yanqi Basin and Kenli County according to the degree of salinity. This study on soil salinity in arid and coastal areas of China will provide a useful reference for future research on soil salinity both in China and globally.
\end{abstract}

Keywords: salinization; feature space; remote sensing inversion; coastal areas; arid areas; applicability

\section{Introduction}

Land degradation is a major global environmental problem [1-3]. Soil salinization, an important element of land degradation, significantly impacts the global ecological environment. Soil salinization is disturbed by the natural environment and human activities when capillary action or evapotranspiration leads to the rise of groundwater and the accumulation of soluble salts at the surface, resulting in different degrees of salinization [4]. Soil salinization not only leads to a decrease in soil fertility, acid-base imbalance, and an increasingly poor land environment but also intensifies the conflict between socioeconomic development and environmental protection [5]. Therefore, it is important to extract soil salinization information dynamically, quickly, and accurately on a regional scale, monitor the spatial distribution characteristics of saline soils, and quantify the degree of soil salinization to manage soil salinization and prevent further deterioration of the ecological environment. Managing soil salinization provides security for the development of efficient agriculture, working towards achieving the goal of sustainable development of agricultural production and the social economy. 
Current salinization research is mostly focused on semi-arid and arid regions, and coastal areas. As a typical area of coastal soil salinization in China [6], the Yellow River Delta has a shallow groundwater depth and uneven spatial distribution of mineralization, complex regional water-salt dynamic processes, and serious re-salinization phenomena. The difficulty in using this moderately to severely salinized soil seriously restricts the development and utilization of land resources and the sustainable socioeconomic development of the Yellow River Delta.

The primary and secondary salinization of soils in arid and semi-arid regions is an increasingly prominent problem. With the large-scale farmland reclamation and the promotion of dropper technology, ecological problems such as reduced irrigation water and increased soil salinization have emerged, which seriously restrict oasis agriculture and socioeconomic development [7]. However, few studies are available on the universality of soil salinity inversion models using feature space for coastal versus inland drylands.

In this study, we used Kenli County of the Yellow River Delta, a coastal area, and the Yanqi Basin, an arid inland area, as the research areas. We will use the feature space method combined with field survey data and Landsat 8 OLI images to quantitatively invert the distribution pattern of salinization. We will then determine the most suitable two-region model by analyzing and comparing the applicability of the three models to different geographic environments and different causes of salinization. Our study hopes to provide a scientific basis for future sustainable development and utilization of land resources, ecological environmental protection, and dynamic monitoring of salinization.

This study answers the following research questions (RQs):

RQ 1: Which is the best performing feature space model for the inversion of salinization in the Yanqi basin and the Yellow River delta region?

RQ 2: Are the models that are suitable for the dynamic monitoring of salinization in arid and coastal areas consistent?

RQ 3: Which factors are the most influential in the development of salinization in the Yellow River Delta and the Yanqi Basin?

RQ4: What are the main recommendations for the management of salinized areas in both regions?

This study includes five more sections. The second section presents literature related to the application of remote sensing technology for salinization monitoring and establishes the objective of the present research. The third section explains the research methodology, including information about the data used, salinization evaluation index, and the feature space method that has been applied to define salinization classification models. Section 4 presents the obtained results. Finally, Sections 5 and 6 focus on explaining the achieved results, comparing them with other studies, highlighting the limitations and main conclusions of this study, and providing suggestions for future lines of work.

\section{Related Work}

Numerous studies in the existing literature have sought to build tools whose purpose is to monitor soil salinization dynamically and accurately. variables. The global salinization area is vast $[8,9]$, and the traditional point survey method for monitoring soil salinization is costly and time-consuming. Therefore, monitoring soil salinization using remote sensing is of great scientific and practical significance for achieving global sustainable development [10,11]. Since the 1970s, analysis of soil salinization using remote sensing data from multiple sources has been getting increasing attention. In 2007, Brunner et al. [12] studied the Bosten Lake area in Xinjiang to evaluate soil salinity using the NDVI index and obtained a soil salinity distribution map.In 2013, Madani et al. [13] studied the Siwa oasis in the western desert of Egypt using Landsat data, wherein they converted the Digital Number (DN) values of the image into reflectance and obtained a strong correlation between soil salinity, short-wave, and thermal infrared bands. In 2016, Azabdaftari et al. [14] extracted the Normalized Difference Vegetation Index (NDVI), Ratio Vegetation Index (RVI), Soil-Adjusted Vegetation Index (SAVI), Normalized Difference Snow Index (NDSI), 
and other indexes using Landsat in Adana, Turkey. In order to create a soil salinity map of the area, field-measured conductivity data were used to analyze the relationship between the original image band values and those of different indices In 2019, Hoa et al. [15] selected the Gaussian Process (GP) through a multi-machine learning model comparison using Sentinel-1A data to map the distribution of soil salinity in the Mekong Delta.

In summary, most scholars have used supervised and unsupervised classification, automatic neural network extraction, and other research methods to study the dynamic monitoring and spatiotemporal characteristics of salinization areas $[16,17]$. These semiautomatic classification methods are time-consuming, labor-intensive, inefficient, have long decoding periods, and are subject to a high degree of subjective influence; therefore, it is difficult to use them to conduct long-term series salinization dynamic monitoring. Using various types of indicators in multispectral remote sensing data to construct a feature space for extracting and monitoring salinization information, is an advanced method for salinity remote sensing monitoring research. Many scholars are now using indicators closely related to soil salinity to establish feature spaces to extract soil salinization information and have achieved positive results. Wang et al. [18] proposed the NDVI-SI feature space concept by considering both vegetation and soil information; they used the normalized difference vegetation index (NDVI) and salinity index (SI) to quantitatively analyze and monitor salinization in Xinjiang Yutian Oasis. Ha et al. [19] selected SI and surface reflectance (Albedo) to build a feature space and construct a model to extract information on the distribution of soil salinization in the Kriya Oasis. Ding et al. [20] used Landsat -TM data to analyze the relationship between saline soils, the Modified Soil-adjusted Vegetation Index (MSAVI), and Wetness Index (WI). Subsequently, they proposed the MSAVI-WI feature space and a remote sensing monitoring index model for soil salinity.

Spectral feature space is an effective modern method for the inversion of surface parameters using multi-band or multi-indicator synergistic changes with simple and feasible model indicators that are easy to extract. This method is widely used in research on surface evapotranspiration, crop water content, and for monitoring soil moisture, droughts, and desertification [21]. Recently the feature space model method has been applied for the inversion of soil salinization parameters with promising results [22,23].

The above literature review demonstrates the successful application of remote sensing techniques in monitoring salinity-related problems. However, the following research gaps were observed: (1) most studies used a single evaluation index or a particular feature space model for monitoring salinity and did not compare multiple special spatial models; (2) in a previous study, the authors built the optimal inversion model in only one area, the Yellow River Delta, and they did not conduct a model applicability analysis in different geographical locations.

In response to these gaps in the literature, the objectives of this study are as follows: (1) to establish a quantitative model that combines soil spectral and vegetation biophysical characteristics, and soil salinity to determine the parameters suitable for salinity inversion in the two regions, and analyze the general applicability of the feature space model to achieve a quantitative inversion and dynamic monitoring of soil; (2) and to determine the different drivers of salinity in the Yellow River Delta and the Yanqi Basin and propose recommendations for the prevention and control of salinity in key areas for protecting ecosystems and maintaining sustainable agricultural development.

\section{Materials and Methods}

\subsection{Overview of the Study Area}

In this study, two study areas were selected: Kenli County in the Yellow River Delta, a coastal saline area, and the Yanqi Basin, an arid saline area.

The Yellow River Delta, located in northern Shandong Province, is an alluvial plain formed by sediment carried by the Yellow River Estuary in the coastal zone. Kenli County is in the Yellow River Estuary. The coordinate range is between $37^{\circ} 24^{\prime}-38^{\circ} 10^{\prime} \mathrm{N}$ and $118^{\circ} 15^{\prime}-119^{\circ} 19^{\prime} \mathrm{E}$ (Figure 1). According to the Chinese climate zones, it has an area of 
approximately 233,100 ha and is categorized as a humid zone. The landform type is influenced by the repeated diversion of the Yellow River and sediment deposition into the sea and is thus very complex; the terrain is slightly lowered in a fan shape from the southwest to the northeast [24]. Because of the influence of the continental monsoon, the distribution of precipitation in this area is not uniform and is mostly concentrated in the summer. The average annual precipitation is $530-630 \mathrm{~mm}$, the average annual evaporation is $1750-2430 \mathrm{~mm}$, and the ratio of evaporation to rainfall of approximately 3.5:1. Most of the soil types are fragile saline and tidal soils. Saline soil is primarily distributed in the area with a phreatic water level of 1-2 $\mathrm{m}$ and a salinity of 10-30 g/L, and the high content of soluble salts in the soil is not conducive to crop growth. The main crops are wheat, corn, cotton, and rice, with low yields. There is a large distribution of salt wasteland and serious confusion in the soil spectrum.

The Yanqi Basin, in the northeast of the Tarim Basin, is a semi-enclosed mountain basin. The coordinate range is between $41^{\circ} 45^{\prime}-42^{\circ} 15^{\prime} \mathrm{N}$ and $85^{\circ} 30^{\prime}-88^{\circ} 15^{\prime} \mathrm{E}$ (Figure 1). According to the Chinese climate zone, it has an area of approximately 1,300,400 ha and is categorized as an arid zone, with typical arid zone oasis characteristics, such as large daily differences in temperature, low precipitation, high evaporation, and dry air. The northern part of the area is a flooded micro-slope plain, the middle contains Bosten Lake, and the east is flowing sand dunes. The terrain is high in the west, low in the east, high in the north, and low in the south, and the Kaidu River runs from west to east into Bosten Lake. The region is affected by a continental desert climate, with an average annual precipitation of $50-80 \mathrm{~mm}$, average annual evaporation of 2000.5-2449.7 mm, and an evapotranspiration ratio greater than 30:1. Under this specific environment, underground runoff and salinity lack outlets, and soil salinization is more common [25]. The soil types are mainly brown desert, meadow, tidal, saline, and weathered soil [26] and are nutrient deficient, which adversely affects local agricultural production. The main crops are corn, tomato, and pepper.

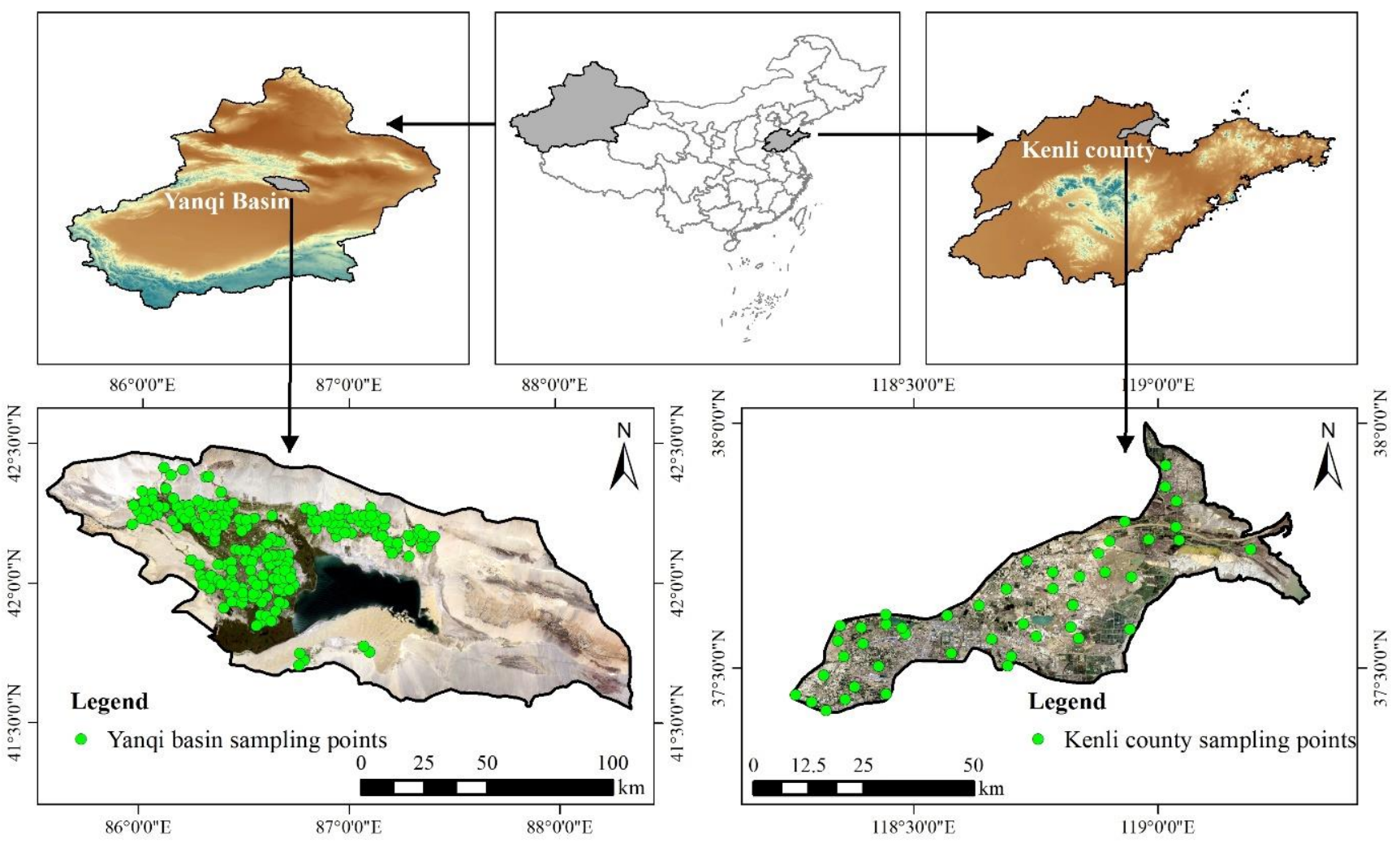

Figure 1. Geographical location and filed survey point distribution in the study area. 


\subsection{Data Sources}

\subsubsection{Remote Sensing Image Data}

Landsat 8 Operational Land Imager (OLI) satellite data launched by the National Aeronautics and Space Administration (NASA) was selected as the data source. The imager has nine bands, a coving width of $185 \times 185 \mathrm{~km}$, and a resolution of $30 \mathrm{~m}$. The Landsat 8 OLI satellite remote sensing image on 30 April 2020, was selected for the Yanqi Basin, and 29 April 2019, was selected for Kenli County and the Yellow River Delta because these two areas experience abundant evaporation and annual soil moisture lows during springtime, and salt in the soil gathered on the surface. Additionally, farmlands have not been cultivated in the spring, and the soil is mostly covered by sparse ground vegetation.

\subsubsection{Field Sampling Data}

The data of the measured sample points of the two areas included soil salinity and soil conductivity data. The sampling points of the field-measured verification data were evenly distributed among the farmlands in Kenli County and the Yanqi Basin. The sampling data for Kenli County (47) were acquired on-site by the research team in April 2019, and sampling data for the Yanqi Basin (221) were acquired on-site by the research team in May 2020. Sample points were evenly distributed throughout the Kenli and the Yanqi basin areas (Figure 2). The coordinates of the sample points were measured by GPS in the field with centimeter-level accuracy. Three soil samples were randomly selected within $25 \mathrm{~m}^{2}$ of each sampling point, mixed, and placed in a sampling bag for subsequent physical and chemical analyses. The soil sampling depth was $0-20 \mathrm{~cm}$, and approximately $1000 \mathrm{~g}$ of soil was taken at each sampling point. The salinity content was averaged from multiple measurements taken at the same site using a LeiCi DDS-307 (ShengKe, ShangHai, China) to ensure the reliability of the results.

\subsection{Methods}

The technical flowchart of this study shows the main ideas of this research (Figure 2).

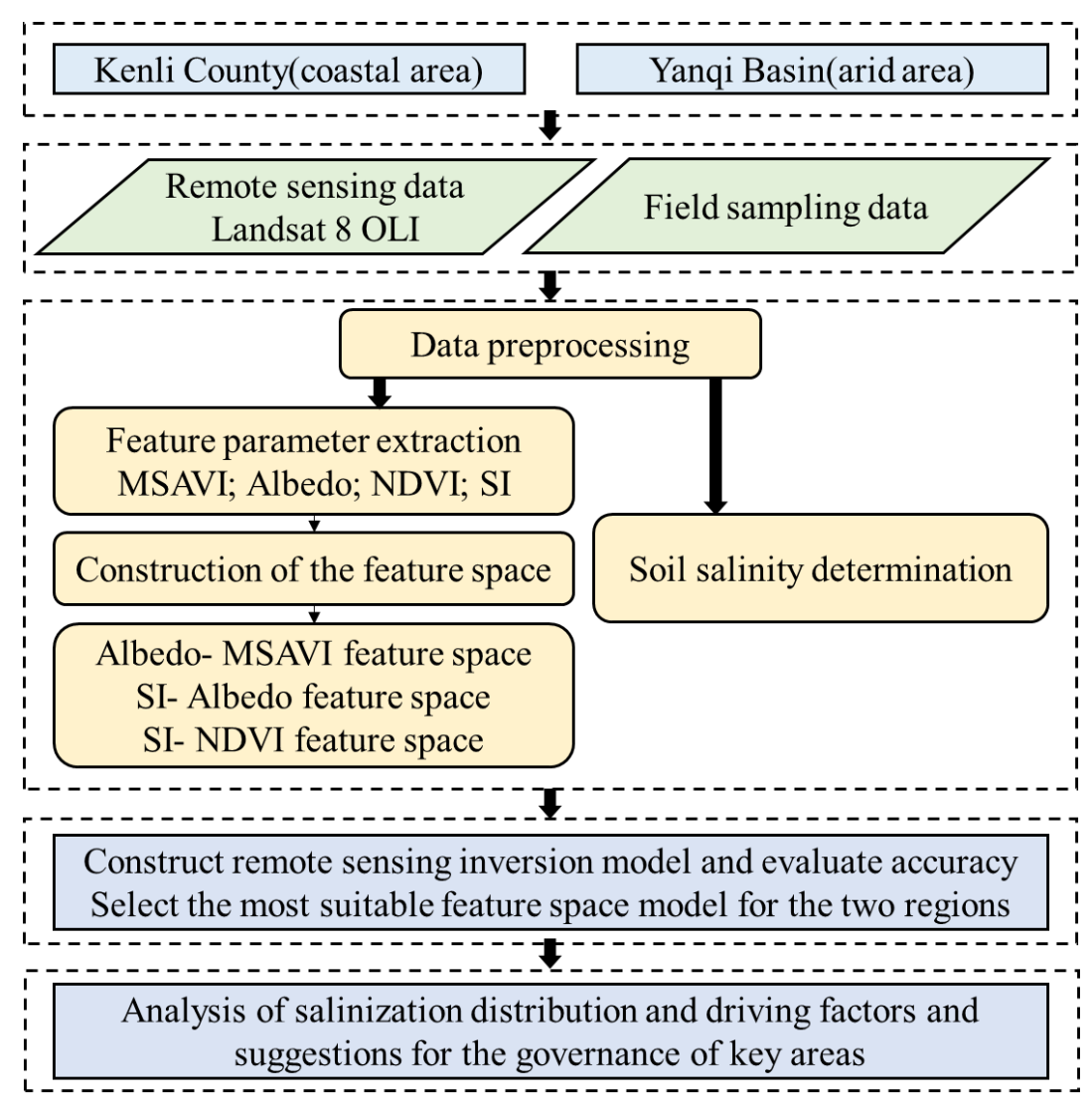

Figure 2. The technical flowchart of this study. 


\subsubsection{Feature Parameter Extraction}

In our study, we used different parameters that can be extracted to measure salinity in the two regions.

\section{Modified Soil-Adjusted Vegetation Index (MSAVI)}

The modified soil-adjusted vegetation index (MSAVI) considers the bare soil line, which can better eliminate or reduce the influence of soil and vegetation canopy background and thus better indicate the vegetation information in the study area. High soil salinity inhibits crop growth and results in low vegetation cover, which means that MSAVI decreases with increasing soil salinity, and therefore, it can be used as a biophysical parameter to reflect vegetation growth. The MSAVI was used to extract vegetation information, as shown in Formula (1) [22]:

$$
M S A V I=\frac{(2 N I R+1)-\sqrt{(2 N I R+1)^{2}-8(N I R-R)}}{2},
$$

where NIR and $R$ represent the reflectivity values of the near-infrared and red bands in the OLI image, respectively.

\section{Albedo}

Surface albedo is an indicator of the absorption and reflection ability of the ground to solar radiation and refers to the ratio of surface-reflected radiation to incident radiation. A higher albedo indicates a higher reflectivity and, thus, a smaller absorption capacity of the ground to solar radiation. Surface albedo can reveal information about salinized soil. In this study, we used the inversion formula of albedo established by Liang [19], as shown in Formula (2):

$$
\text { Albedo }=0.356 B+0.13 R+0.373 N I R+0.085 S R 1+0.072 S R 2-0.0018,
$$

where $B, R, N I R, S R 1$, and $S R 2$ correspond to the reflectivity values of blue, red, nearinfrared, short-wave infrared band 1 , and short-wave infrared band 2, respectively, in the OLI image.

\section{Normalized Difference Vegetation Index (NDVI)}

The normalized difference vegetation index $(N D V I)$ is often used to extract vegetation information to indirectly characterize soil salinity [18]. The NDVI is very sensitive to the performance of green vegetation and can eliminate most of the changes in irradiance related to instrument calibration, solar angle, terrain, cloud shadow, and atmospheric conditions. Higher NDVI values indicate more green vegetation. We used NDVI as an indicator to monitor soil salinization, as shown in Formula (3):

$$
N D V I=\frac{N I R-R}{N I R+R}
$$

where NIR and $R$ represent the reflectivity values of the near-infrared and red bands in the OLI image, respectively.

\section{Salinity Index (SI)}

The salinity index $(S I)$ is an important factor for describing soil salinization [27]. We used SI to extract salt information, as shown in Formula (4):

$$
S I=\sqrt{B \times R},
$$

where $B$ and $R$ represent the reflectivity values of the blue and red bands in the OLI image, respectively. 


\subsubsection{Data Normalization Processing}

The maximum and minimum values of MSAVI, Albedo, SI, and NDVI were calculated using The Environment for Visualizing Images (ENVI) statistical tools. Then, data normalization was performed using the ENVI data, as shown in Formulas (5)-(8):

$$
\begin{gathered}
M=\frac{M S A V I-M S A V I_{\min }}{M S A V I_{\max }-M S A V I_{\min }} \times 100 \%, \\
A=\frac{\text { Albedo }-A l b e d o_{\min }}{A l b e d o_{\max }-A l b e d o_{\min }} \times 100 \%, \\
S=\frac{S I-S I_{\min }}{S I_{\max }-S I_{\min }} \times 100 \%, \\
N=\frac{N D V I-N D V I_{\min }}{N D V I_{\max }-N D V I_{\min }} \times 100 \%,
\end{gathered}
$$

where $M$ is the normalized value of the MSAVI, $A$ is the normalized Albedo, $N$ is the normalized NDVI, and $S$ is the normalized SI.

\subsubsection{Feature-Space Principle}

The feature space is a spatial system composed of two or more bands or spectral indicators used to measure the spectral characteristics of ground parameters in remote sensing images [28]. For extracting thematic information of salinization and constructing a feature space model, having a reasonable selection of characteristic parameters of the spectral response of salinized soil is vital. We constructed three feature spaces using different combinations of the parameters described above.

\section{Albedo-MSAVI Feature Space}

There is a significant relationship between the occurrence of saline soil and the characteristic parameters of the soil spectrum. The Albedo-MSAVI feature space [29] shown in Figure 3a shows that there is a non-linear relationship between albedo and MSAVI. As albedo increased, the degree of soil salinization increased, and MSAVI decreased. Point $A$ in Figure 3a represents heavily salinized land with low vegetation coverage and high surface albedo (low MSAVI and high albedo); point $B$ represents bare land, and point $C$ represents a high vegetation coverage area with relatively low albedo and sufficient soil moisture content (high MSAVI and low albedo). As can be seen, the surface evapotranspiration resistance, soil salt content, and albedo decreased with an increase in surface vegetation coverage.

SI-Surface Albedo (SI-Albedo) Feature Space

As shown in Figure 3b, the SI- albedo feature space demonstrates that SI and surface albedo exhibit significant linear characteristics [19]; where an increase in SI increases surface albedo and the severity of salinization.

\section{SI-NDVI Feature Space}

The SI-NDVI feature space [18], shown in Figure 3c, demonstrates a non-linear relationship between SI and NDVI. As salinity content increased, the vegetation coverage declined, and the degree of salinity gradually increased. Point A in Figure $3 \mathrm{c}$ represents heavily salinized land with high soil salinity and low vegetation coverage, point $B$ represents bare land, and point $C$ represents a high vegetation coverage area. 


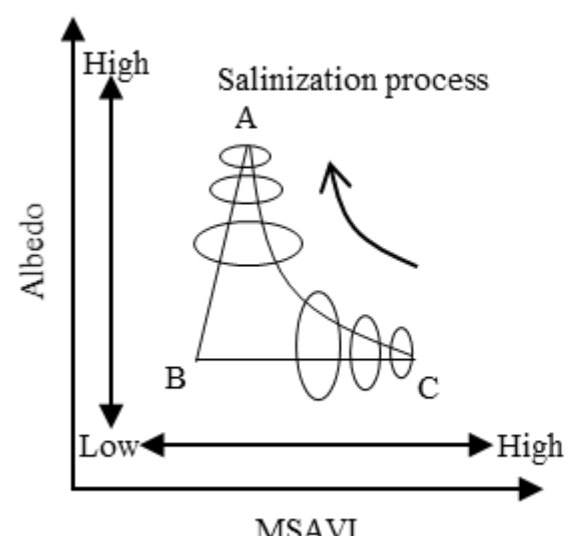

(a)

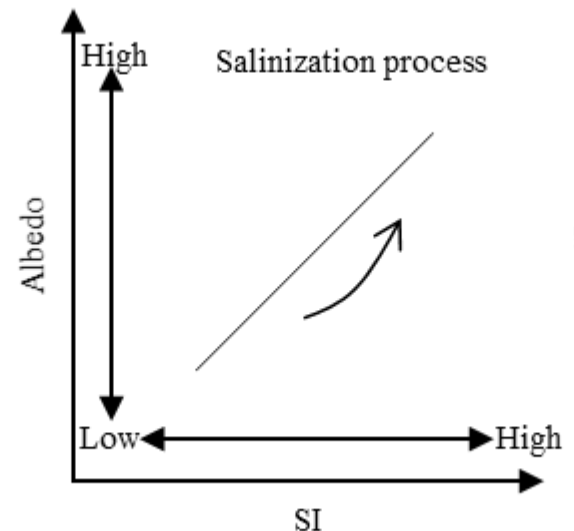

(b)

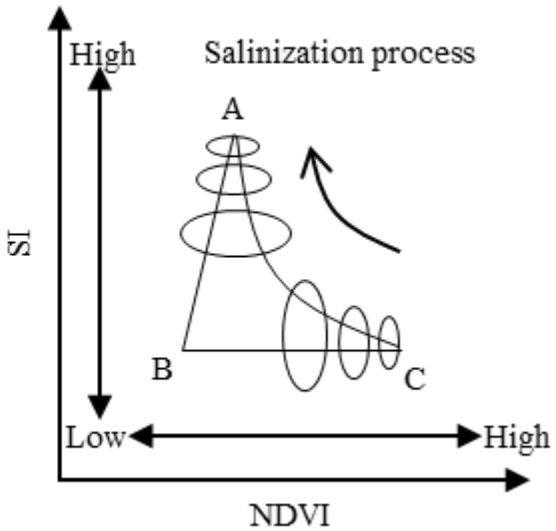

(c)

Figure 3. Principle of feature space. (a)Albedo-MSAVI; (b) SI-Albedo; (c) SI-NDVI.

\subsubsection{Construction of the Feature Space Inversion Models}

Albedo-MSAVI Feature Space Inversion Model

To establish a two-dimensional scatter plot, the Albedo-MSAVI feature space inversion model took normalized MSAVI as the horizontal axis and normalized albedo as the vertical axis. Figures $4 \mathrm{a}$ and $5 \mathrm{a}$ show that there is a non-linear relationship between surface albedo and MSAVI, similar to that shown in Figure 3a. Taking the MSAVI and albedo coordinates $(0,1)$ as reference points in Figure $4 \mathrm{a}$, the distance from any point in the scatter diagram to the reference point reflects the degree of salinization. Shorter distances signified a greater degree of salinization and vice versa. In the two-dimensional feature space, the distance from any point to the $(0,1)$ point was $\mathrm{D}$, and a remote sensing monitoring model was constructed on this basis, as shown in the following Equation (9):

$$
\text { Albedo }-M S A V I=\sqrt{(1-\text { Albedo })^{2}+M S A V I},
$$

\section{SI-Albedo Feature Space Inversion Model}

The SI-Albedo feature space inversion model used the normalized SI as the horizontal axis and normalized albedo as the vertical axis to establish a two-dimensional scatter plot. As shown in Figures $4 \mathrm{~b}$ and $5 \mathrm{~b}$, the scatter diagram shows a band-like distribution like that in Figure 3b. With increasing SI, the degree of salinization increased. The reference point was the point with an SI and surface albedo of 0 . The closer any point was to this point in the scatter diagram, the lower the degree of soil salinization and vice versa. The distance from any point in the two-dimensional feature space to the $(0,0)$ point was $\mathrm{D}$; a remote sensing monitoring model was built on this basis, as shown in Equation (10):

$$
S I-\text { Albedo }=\sqrt{S I^{2}+\text { Albedo }} .
$$

\section{SI-NDVI Feature Space Inversion Model}

The SI-NDVI feature space inversion model considers NDVI as the horizontal axis and normalized SI as the vertical axis to establish a two-dimensional scatter plot, as shown in Figures $4 c$ and $5 c$. Considering the NDVI and SI coordinates $(1,0)$ as the reference point, greater distances from this point in the scatter diagram indicate greater soil salinization (similar to Figure 3c). In the two-dimensional feature space, the distance from any point to the $(1,0)$ point was $D$, and a remote sensing monitoring model was constructed based on this, as shown in Equation (11):

$$
S I-N D V I=\sqrt{(N D V I-1)^{2}+S I^{2}} .
$$




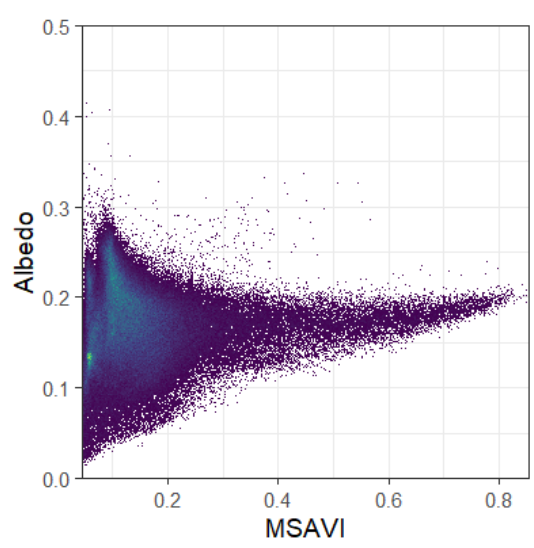

(a)

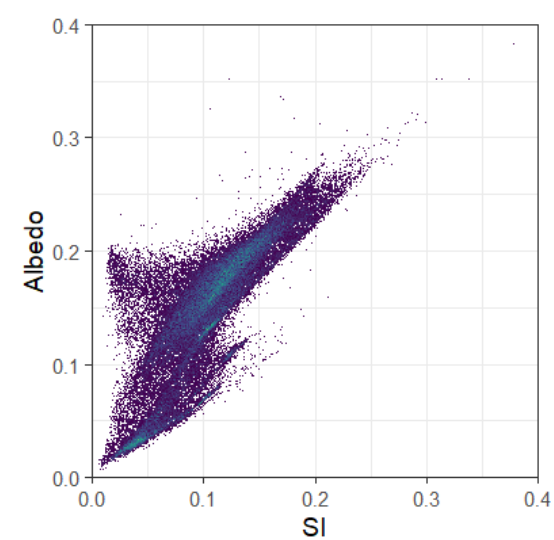

(b)

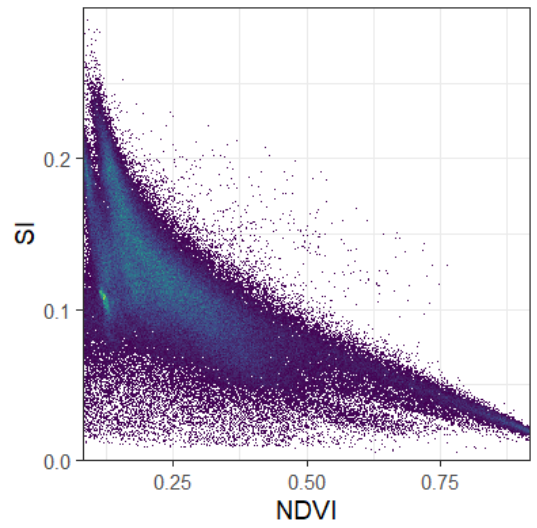

(c)

Figure 4. Scatter diagrams of the feature spaces in Kenli County. (a) Albedo-MSAVI; (b) SI-Albedo; (c) SI-NDVI.

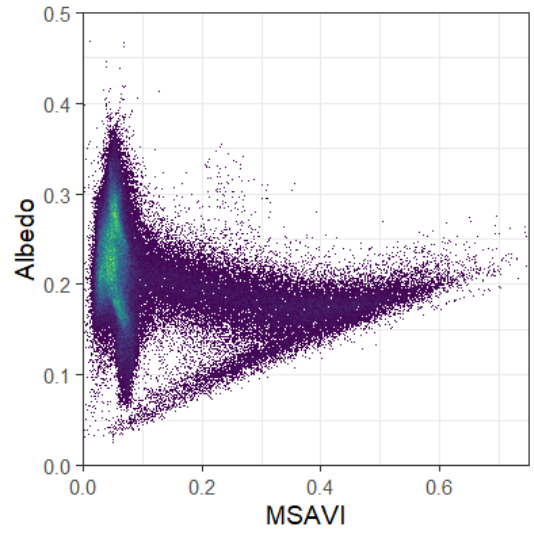

(a)

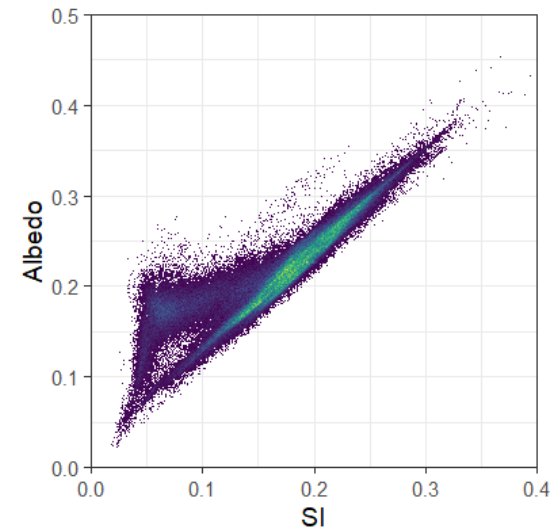

(b)

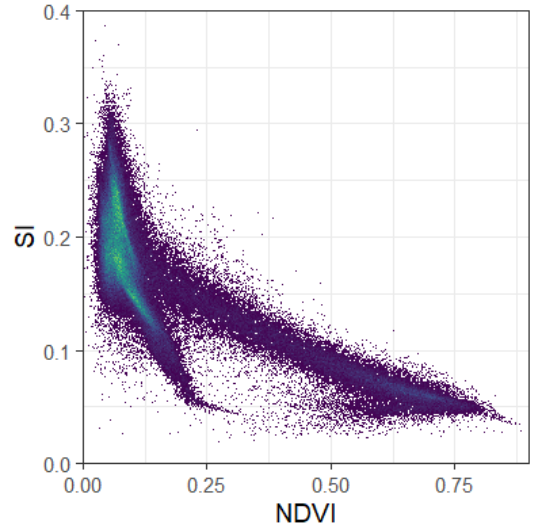

(c)

Figure 5. Scatter diagrams of the feature spaces in the Yanqi Basin. (a) Albedo-MSAVI; (b) SI-Albedo; (c) SI-NDVI.

\section{Results}

\subsection{Inversion Results and Classifications}

In this study, we classified the degree of soil salinity according to the Jenks natural break method. Compared to other classification methods, such as goodness-of-fit, the Jenks natural break classification method has the advantage of having the least variance within classes and the greatest variance between classes and was thus able to minimize the sum of variance within each salinity class [30]. The modeled Albedo-MSAVI, SI-Albedo, and SI-NDVI values were divided into five classes, resulting in five value range intervals. Salinization monitoring indicators of Kenli County in 2019 were divided into five categories. In the Albedo-MSAVI model the categories were as follows: non-salinized soil (value $<0.85$ ), mild salinized soil (value $0.85-0.88$ ), moderately salinized soil (value $0.88-0.89$ ), severe salinized soil (value 0.89-0.90), and saline soil (value 0.90-0.98). In the SI-Albedo model the categories were as follows: non-salinized soil (value $<0.17$ ), mild salinized soil (value $0.17-0.23$ ), moderately salinized soil (value $0.23-0.29$ ), severe salinized soil (value $0.29-0.35$ ), and saline soil (value 0.35-0.60). In the SI-NDVI model the categories were as follows: non-salinized soil (value < 0.56), mild salinized soil (value 0.56-0.61), moderately salinized soil (value 0.61-0.66), severe salinized soil (value 0.66-0.69), and saline soil (value 0.69-0.90) (Table 1). 
Table 1. Salinization monitoring indicators of Kenli County in 2019.

\begin{tabular}{cccccc}
\hline $\begin{array}{c}\text { Feature Space } \\
\text { Inversion Model }\end{array}$ & $\begin{array}{c}\text { Non- } \\
\text { Salinization }\end{array}$ & $\begin{array}{c}\text { Mild } \\
\text { Salinization }\end{array}$ & $\begin{array}{c}\text { Moderate } \\
\text { Salinization }\end{array}$ & $\begin{array}{c}\text { Severe } \\
\text { Salinization }\end{array}$ & Saline Soil \\
\hline Albedo-MSAVI & $\leq 0.85$ & $>0.85, \leq 0.88$ & $>0.88, \leq 0.89$ & $>0.89, \leq 0.90$ & $>0.90, \leq 0.98$ \\
SI-Albedo & $\leq 0.17$ & $>0.17, \leq 0.23$ & $>0.23, \leq 0.29$ & $>0.29, \leq 0.35$ & $>0.35, \leq 0.60$ \\
SI-NDVI & $\leq 0.56$ & $>0.56, \leq 0.61$ & $>0.61, \leq 0.66$ & $>0.66, \leq 0.69$ & $>0.69, \leq 0.90$ \\
\hline
\end{tabular}

Salinization monitoring indicators of the Yanqi Basin in 2020 were divided into five categories. In the Albedo-MSAVI model the categories were as follows: non-salinized soil (value $<0.29$ ), mild salinized soil (value $0.29-0.44$ ), moderately salinized soil (value $0.44-0.64$ ), severe salinized soil (value $0.64-0.87$ ), and saline soil (value $0.87-1.40$ ). In the SI-Albedo model, the categories were as follows: non-salinized soil (value $<0.50$ ), mild salinized soil (value $0.50-0.72$ ), moderately salinized soil (value $0.72-0.93$; severe salinized soil (value 0.93-1.15), and saline soil (value 1.15-1.41). In the SI-NDVI model the categories were as follows: non-salinized soil (value $<0.32$ ), mild salinized soil (value $0.32-0.57$ ); moderately salinized soil (value $0.57-0.76$ ), severe salinized soil (value $0.76-0.93$ ), and saline soil (value 0.93-1.19). (Table 2).

Table 2. Salinization monitoring indicators of the Yanqi Basin in 2020.

\begin{tabular}{cccccc}
\hline $\begin{array}{c}\text { Feature Space } \\
\text { Inversion Model }\end{array}$ & $\begin{array}{c}\text { Non- } \\
\text { Salinization }\end{array}$ & $\begin{array}{c}\text { Mild } \\
\text { Salinization }\end{array}$ & $\begin{array}{c}\text { Moderate } \\
\text { Salinization }\end{array}$ & $\begin{array}{c}\text { Severe } \\
\text { Salinization }\end{array}$ & Saline Soil \\
\hline Albedo-MSAVI & $\leq 0.29$ & $>0.29, \leq 0.44$ & $>0.44, \leq 0.64$ & $>0.64, \leq 0.87$ & $>0.87, \leq 1.40$ \\
SI-Albedo & $\leq 0.50$ & $>0.50, \leq 0.72$ & $>0.72, \leq 0.93$ & $>0.93, \leq 1.15$ & $>1.15, \leq 1.41$ \\
SI-NDVI & $\leq 0.32$ & $>0.32, \leq 0.57$ & $>0.57, \leq 0.76$ & $>0.76, \leq 0.93$ & $>0.93, \leq 1.19$ \\
\hline
\end{tabular}

ArcGIS was used to extract salinity information and generate salinity grade distribution maps for the three monitoring models of Kenli County (Figure 6) and the Yanqi Basin (Figure 7). All three models of Kenli County showed that the region has a high level of salinization, among which the Albedo-MSAVI and SI-NDVI inversion distribution maps showed larger areas of moderate and severe salinization, mainly concentrated in the southwest and northeast; mild salinization was less common and mainly distributed in the central region. Overall, the degree of salinization gradually increased from east to west.

In the SI-Albedo inversion distribution map, moderate and severe salinization were mainly distributed in the central region and some coastal areas; mild salinization was mainly distributed on both sides of the Yellow River and near rivers and lakes; and nonsalinized areas were mainly distributed on both sides of the Yellow River, which is consistent with the results of Zhang et al. [31,32]. Moving west from the coast, the degree of salinization increases from mild salinity to moderate salinity and then to severe salinity, and the overall degree of salinization shows a high-low-high trend, meaning, the coastal and inland marginal areas were the most heavily salinized whereas the central areas were mildly salinized.

The distribution of salinization in the Yanqi Basin differs greatly among the three models. In the SI-Albedo inversion distribution map, moderate salinization and severe salinization were mainly distributed in the eastern part of Heshuo County, the Yellow Water Ditch irrigation area, the inlet of Bosten Lake, and the southern shore of Bosten Lake. In contrast, mild salinization was mainly distributed on the banks of the Kaidu River and around the dense drainage system of Bosten Lake. The non-salinization areas were mainly located in the southern part of Yanqi County, the middle and lower reaches of the Nangan canal, and the southeast edge of the basin. From east to west, the salinization degree is distributed along the water system echelon, and the degree of salinization is generally in a high-low-high direction; meaning, the northern and southern marginal areas of the basin were the most salinized, and the central areas were mildly salinized. 


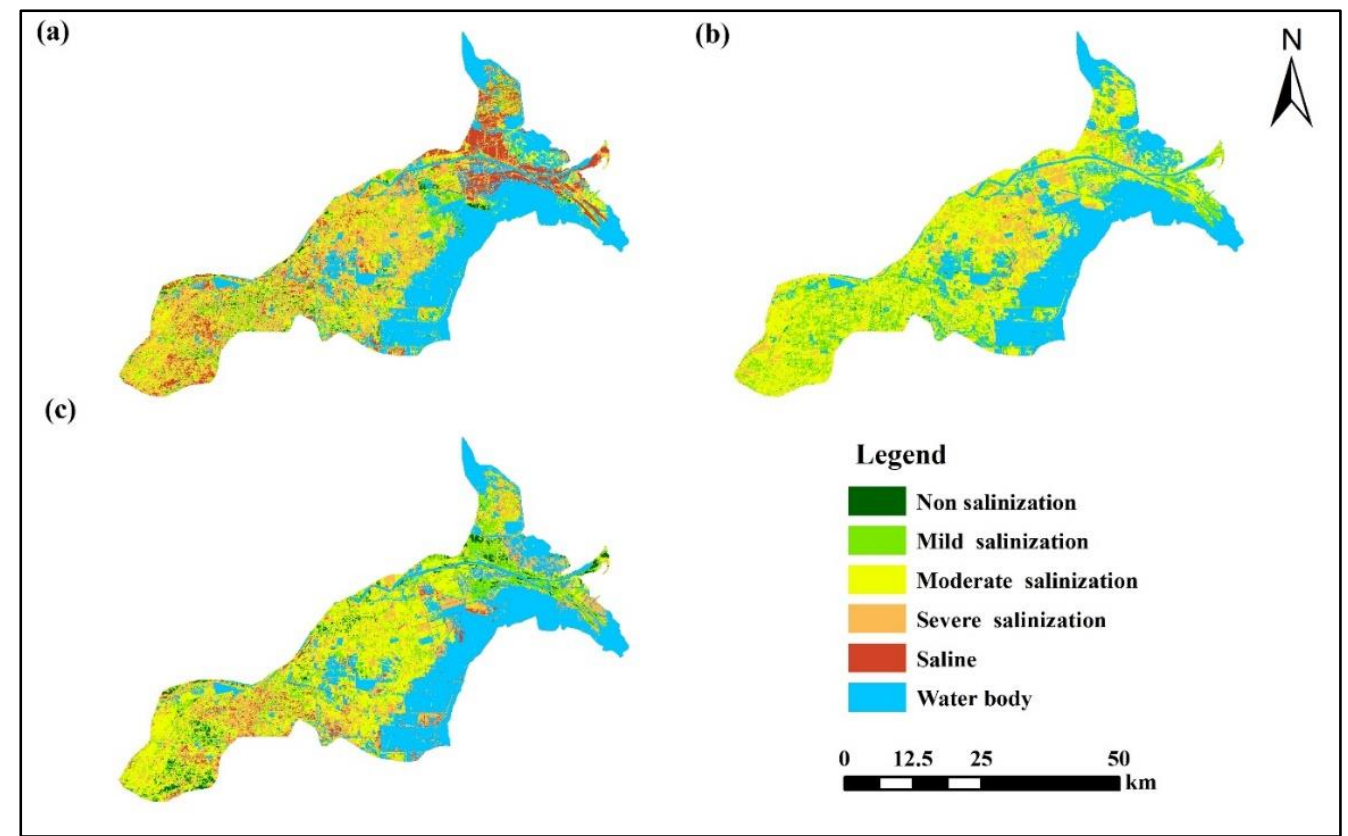

Figure 6. Distribution of salinization in Kenli County (a): Albedo-MSAVI, (b): SI-Albedo, (c): SI-NDVI.

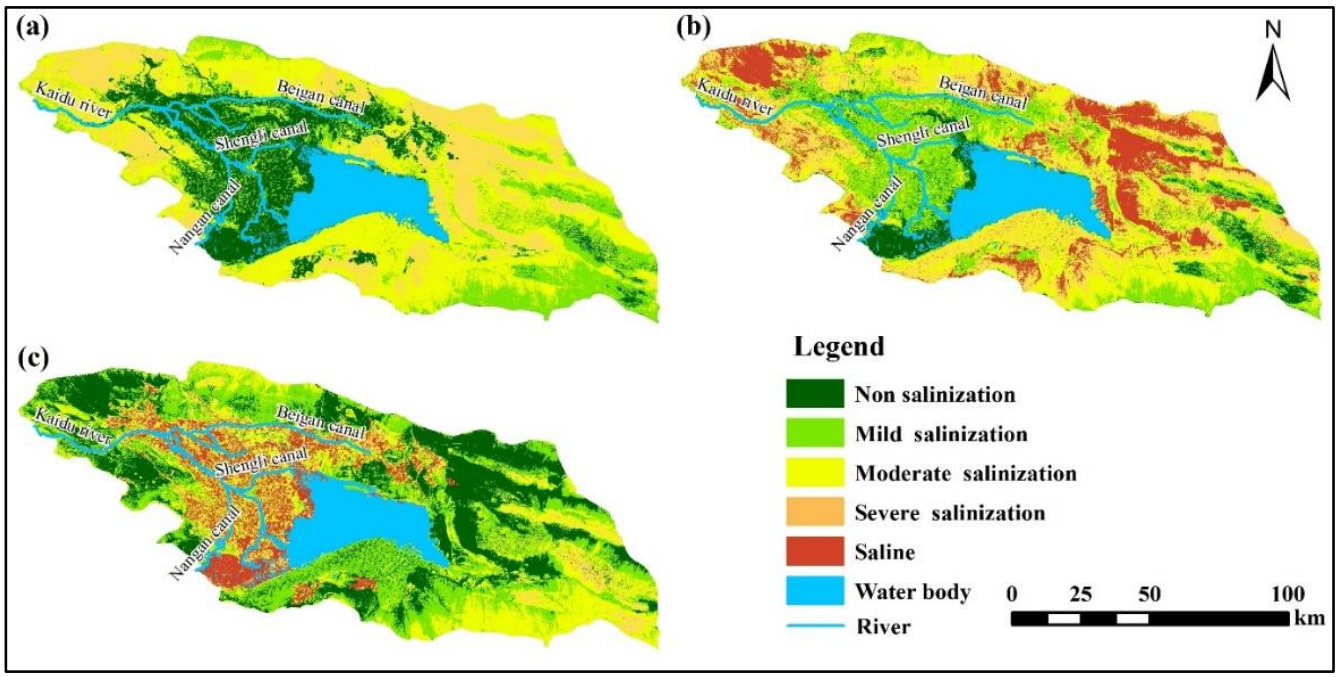

Figure 7. Distribution of salinization in the Yanqi Basin (a): Albedo-MSAVI, (b): SI-Albedo, (c): SI-NDVI.

\subsection{Model Accuracy Analysis}

According to the Chinese soil salinization grading standard, and referring to "Soil Agricultural Chemical Analysis and Methods" by Lu et al. [33], the degree of soil salinization in coastal areas can be divided into the following five categories: non-salinized soil (soil salinity $<1.0 \mathrm{~g} \mathrm{~kg}^{-1}$ ), lightly salinized soil (soil salinity $1.0-2.0 \mathrm{~g} \mathrm{~kg}^{-1}$ ), moderately salinized soil (soil salinity 2.0-4.0 $\mathrm{g} \mathrm{kg}^{-1}$ ), heavily salinized soil (soil salinity $4.0-6.0 \mathrm{~g} \mathrm{~kg}^{-1}$ ), and saline soil (soil salinity $>6.0 \mathrm{~g} \mathrm{~kg}^{-1}$ ). Referring to Soil of Xinjiang [34], the degree of soil salinization in arid and semi-arid areas can be divided into the following five categories: non-salinized soil (soil salinity $<3.0 \mathrm{~g} \mathrm{~kg}^{-1}$ ), lightly salinized soil (soil salinity $3.0-6.0 \mathrm{~g} \mathrm{~kg}^{-1}$ ), moderately salinized soil (soil salinity $6.0-10.0 \mathrm{~g} \mathrm{~kg}^{-1}$ ), intensely salinized soil (soil salinity 10.0-20.0 $\mathrm{g} \mathrm{kg}^{-1}$ ), and saline soil (soil salinity $>20.0 \mathrm{~g} \mathrm{~kg}^{-1}$ ).

We classified the salinization of the field measurement sample data according to these standards. The accuracy of the Albedo-MSAVI, SI-Albedo, and SI-NDVI feature space monitoring models was determined by comparing the salinity of the measured values with the salinity of the predicted values of each model (Table 3). 
Table 3. Accuracy verification of the models.

\begin{tabular}{lcccc}
\hline Study Areas & Model & Correct Classification & Wrong Classification & Overall Accuracy \\
\hline \multirow{3}{*}{ Kenli County } & Albedo-MSAVI & 39 & 8 & $82.9 \%$ \\
& SI-Albedo & 41 & 6 & $87.2 \%$ \\
& SI-NDVI & 38 & 9 & $80.9 \%$ \\
\multirow{2}{*}{ Yanqi Basin } & Albedo-MSAVI & 185 & 26 & $87.6 \%$ \\
& SI-Albedo & 197 & 14 & $93.3 \%$ \\
& SI-NDVI & 169 & 42 & $80.1 \%$ \\
\hline
\end{tabular}

The overall classification accuracy of the Albedo-MSAVI feature space monitoring model of Kenli County was $82.9 \%$, compared to $87.2 \%$ for the SI-Albedo feature space monitoring model and $80.9 \%$ for the SI-NDVI feature space monitoring model. In the Yanqi Basin, the overall classification accuracy of the Albedo-MSAVI feature space monitoring model was $87.6 \%$, compared to $93.3 \%$ for the SI-Albedo feature space monitoring model, and $80.1 \%$ for the SI-NDVI feature space monitoring model. Comparing the accuracies of the two study areas, it is clear that the SI-Albedo feature space monitoring model is superior, meaning that $\mathrm{SI}$ and albedo are sensitive parameters for inversion of salinization and are applicable to both the coastal and inland arid areas of China.

According to the monitoring model with the highest precision, Si-Albedo, the ratio of salinized soil to total soil and the degree of salinization are more severe in Kenli County than the Yanqi Basin, with approximately $70 \%$ of the total area impacted by soil salinization. Among the salinized area, the area of moderate salinization was the largest at 54,234 ha, accounting for $29.5 \%$ of the total area of Kenli County, followed by the area of light salinization at 48,371 ha $(26.3 \%)$, heavy salinization at 34,282 ha $(18.7 \%)$, and saline soil at 6979 ha $(4 \%)$. In the Si-Albedo model of the Yanqi Basin, the area of moderate salinization was also the largest at 345,055 ha, accounting for $27.2 \%$ of the total area, followed by heavy salinization at 313,877 ha $(24.7 \%)$, light salinization at 306,924 ha $(24.1 \%)$, and saline soil at 202,934 ha $(15.9 \%)$.

\section{Discussion}

5.1. Feature Space Model Construction and Analysis of Regional Applicability of Remote Sensing Models

This study shows that using feature parameters with clear biophysical significance to construct a feature space can effectively distinguish between different degrees of salinized land. The remote sensing monitoring model can lessen the problem of insufficient monitoring ability by using soil spectral characteristics. In addition, compared to other methods, the model index of this method is simple, feasible, and easy to extract. The feature spatial model method was accurate for modeling soil salinity in China's typical salinization areas (arid and coastal areas), which is conducive to dynamic monitoring of soil salinization. The SI-Albedo feature space monitoring model was more accurate than the Albedo-MSAVI and SI-NDVI models for both regions, indicating that the SI-Albedo feature space model is suitable for coastal and inland dynamic monitoring of salinization and can quickly and accurately extract salinization information. Based on the feature space approach study, the SI-Albedo inversion model has a higher accuracy compared with the Albedo-MSAVI feature space, which was used in the soil salinization study in arid regions by Feng et al. [30], and the NDVI-SI feature space, which was used in the soil salinization study by Wang et al. [18].

The inversion accuracy of this feature space model may be higher because SI and albedo, two important biophysical parameters, directly reflect the degree of salinization and have higher inversion accuracy than the indirect feature parameters (MSAVI and NDVI) they are combined with in the other models. The proportions of moderate salinity, heavy salinity, and saline soil in the Albedo-MSAVI and SI-NDVI inversion models were greater than the measured data, probably because the remote sensing images were selected in spring, and the vegetation index is less sensitive to the extraction of information from vegetation with weaker growth momentum, thus affecting the SI. In addition, the bands in 
which albedo and SI are located are more sensitive to soil salinity, which is not susceptible to the interference of vegetation information, reducing precision [35]. Khan et al. [36] found that the red and blue bands of Landsat images are sensitive to the degree of soil salinity. At the same time, it was concluded from experimental spectral analyses that the SI determined using the red and blue bands of remote sensing images can better reflect the degree of soil salinity.

\subsection{Analysis of Salinization Distribution and Driving Factors and Suggestions for the Governance} of Key Areas

The central and southwestern regions of Kenli County in the Yellow River Delta have dense populations, frequent human construction activities, complex land use structures, a large proportion of agricultural land, and a small proportion of green land and forest land; the exploitation of groundwater due to land use is intensive, which increases the salinization level in these areas. The northeastern region contains the mouth of the Yellow River, where the terrain is low, flat, and prone to seawater backflow, and therefore, salinity tends to accumulate here. In addition, groundwater is generally buried at a shallow depth and has a high degree of mineralization. Salt in groundwater accumulates continuously to the surface through capillary ascension, which results in a high degree of salinization [37]. Non-salinization and mild salinization areas are mainly located near rivers, which may be because the fresh water from rivers (especially the Yellow River) influences the soil, crop irrigation, and drainage, making the soil accumulate less salt with a lesser degree of salinization. This is consistent with the findings of Wang et al. [38]. There is an obvious spatial differentiation pattern of soil salinization in the Yanqi Basin; generally, from west to east and from north to south, soil water content gradually decreases, and soil salt content increases. There is a lot of newly reclaimed arable land in the upper reaches of the Kaidu River, the Yellow Water Ditch irrigation area, and the south shore of Bosten Lake, which poses the problem of leaking canal systems. This leaking increases irrigation and drainage on farmland and raises the groundwater level, which drives evaporation. The salt content of the parent material of the Piedmont proluvial-alluvial fan increases the salinization of the area.

Due to their lower topographic parts and generally less than $3 \mathrm{~m}$ burial depth of groundwater [39], the central alluvial and lakeshore plains are prone to backwater formation, dry climate, strong evaporation, and saline groundwater accumulation to the surface through capillary upwelling, which makes salinization more severe. The non-salinized and lightly salinized areas were mainly located near rivers, which may be because these areas are well equipped with irrigation and drainage facilities, and the land has been improved for many years, making the soil less saline. This is consistent with the results of Wang et al. [40] and Jiang et al. [41] on farmland soil salt distribution patterns and remote sensing inversion in the Yanqi Basin.

Next, we will propose recommendations for the prevention and control of salinity for protecting ecosystems and maintaining sustainable agricultural development. For Kenli County, areas with slightly salinized soil with salt content less than $3 \%$ and good forest site conditions, we recommend implementing simple plowing and leveling and increasing the application of organic fertilizer. For low-lying, poorly drained, and large square connected moderate saline-alkali land, we recommend changing the deep ditch and strip field to a strip field, upper forest, and lower fishing mode. For heavily saline or low-lying land with low terrain and a high water table, we recommend constructing raised fields according to the requirements of planning and design. Where the water table is not too high, the terrain is flat, the soil salt content is high, and the area is large, we recommend implementing open ditch plus concealed pipe alkali drainage projects. For the greening of important nodes such as roads and intersections in the suburbs of cities, the blind ditch drainage model should be used to improve the soil. The southwestern region, the central region, and other areas with lighter soil salinization should pay attention to field preparation, deep pine, and leveling of the soil over time. The eastern region with more serious soil salinization, low-lying terrain, and poor conditions for agricultural development should take advantage 
of the proximity to the sea to develop farming. To build a complete irrigation and drainage system, the middle region should level the land, set up salt drainage ditches to lower the groundwater level, and improve the saline-alkali soil using techniques such as tree pit cushion.

For the Yanqi Basin, in the areas with lightly saline soils in the Kaidu River alluvial plain, agricultural and biological measures should be used to improve saline soils, regulate soil water and salt dynamics, apply more organic fertilizers, loosen the soil tillage layer, ensure the growth and development of productive crops, enhance the effect of salt drenching, reduce evaporation, and inhibit salt reversion. Planting green manure is a key method for improving saline-alkali soils. It can improve the physical and chemical properties of soil, consolidate, enhance the desalination effect, and fertilize the soil. The treatment and improvement of moderate saline-alkali land should use chemical amendments to improve soil, and chemical amendments such as gypsum and zeolite which can effectively reduce the salinity of soil saline-alkali land [42]. In terms of the development and utilization of saline-alkali land and halophytes, the Xinjiang Institute of Ecology and Geography, Chinese Academy of Sciences, sampled many research results and determined that saline-alkali land and halophytes are valuable natural resources. The key to their use is rational development and effective utilization. Physical improvement measures such as land leveling and soil moving improvement can be used to improve severely saline-alkali land, especially land that is difficult to control, such as that at the estuary of Kaidu River and the salt collecting area of Yellow Water Ditch. In addition, using irrigation water to wash the salt to the subsoil layer and draining dissolved salts with a drainage ditch can improve saline-alkali soil. While channel infiltration should be implemented and irrigation management strengthened to wash nutrients from the soil into the groundwater, the drainage system should be built to control the groundwater level and ensure the stable desalination of the soil [43].

Based on the above study and in view of the problems of different types of soil salinization and industrial ecologicalization, four aspects for improving salinized soil should be considered and adopted according to local conditions: water conservancy improvement measures, agricultural improvement measures, biological improvement measures, and chemical improvement measures. In addition, saline land management should be elevated to the level of priority as national food security. The government can set up special public welfare funds to form a complete system for saline land restoration.

\section{Conclusions}

In this study, we combined Landsat 8 OLI remote sensing and field sampling data to address the persistent soil salinization problem in coastal (humid zone) and arid areas (dry zone) of China and constructed Albedo-MSAVI, SI-Albedo, and SI-NDVI feature space inversion models. Our study was the first comparative analysis of the generalizability of feature space inversion models of typical salinization regions of China. The inversion accuracy of the SI-Albedo monitoring model was higher than that of the Albedo-MSAVI and SI-NDVI models in both regions, showing applicability for dynamic monitoring of salinity in coastal and arid regions. We used SI-Albedo to generate a 30-m resolution map of soil salinization in the Yellow River Delta in 2019 and Yanqi Basin in 2020 and analyzed the patterns and drivers of salt distribution. Based on these results and experience, we proposed corresponding sustainable development countermeasures for different types and severities of soil salinization.

However, this technology must be improved. The relationships between remote sensing indices and soil salinity within fields are highly complex; they require further investigation with additional samples and various soil salinity classifications should be used. In this study, the number of study areas was low. Therefore, areas with diverse geographic locations within the same climate zone should be studied to verify the model's general admissibility. Additionally, in this study, sampling was conducted in spring; therefore, seasonal differences in the salinization phenomena could not be considered. 
Thus, the salinity grade map obtained by inversion only represented the current salinity distribution in the region in spring.

In our study, only two climate zones (arid and humid) were investigated. In the follow-up work, we will evaluate the accuracy of salinity inversion for different remote sensing models in other climatic zones transition zone and Qinghai-Tibet Plateau area) in China to more comprehensively assess the applicability of the SI-Albedo remote sensing model across the country.

Author Contributions: Y.F. and H.W. were responsible for the research design, analysis, manuscript design and review; J.L. drafted the manuscript and was responsible for data preparation; experiments and analyses were conducted by J.W.; L.Z. was responsible for funding acquisition and resources; Q.G. was responsible for the research design field survey; manuscript review was done by T.D.; and data curation was completed by Z.Z. and Q.Y. All authors contributed to the editing and reviewing of the manuscript. All authors have read and agreed to the published version of the manuscript.

Funding: This research was funded by the Strategic Priority Research Program (Class A) of the Chinese Academy of Sciences grant number XDA19040501, the National Natural Science Foundation of China: "Rapid Diagnosis Index and Modeling Research in Ratigenization Process of Drip Irrigation Cotton Based on UAV Platform" (Grant No: 31560340).

Institutional Review Board Statement: Not Applicable.

Informed Consent Statement: Not Applicable.

Data Availability Statement: Data sharing not applicable.

Conflicts of Interest: The authors declare no conflict of interest.

\section{References}

1. Periasamy, S.; Ravi, K.P. A novel approach to quantify soil salinity by simulating the dielectric loss of SAR in three-dimensional density space. Remote Sens. Environ. 2020, 251. [CrossRef]

2. Perri, S.; Suweis, S.; Holmes, A.; Marpu, P.R.; Entekhabi, D.; Molini, A. River basin salinization as a form of aridity. Proc. Natl. Acad. Sci. USA 2020, 117, 17635-17642. [CrossRef]

3. Jiang, C.; Zhang, H.; Zhao, L.; Yang, Z.; Wang, X.; Yang, L.; Wen, M.; Geng, S.; Zeng, Q.; Wang, J. Unfolding the effectiveness of ecological restoration programs in combating land degradation: Achievements, causes, and implications. Sci. Total Environ. 2020, 748. [CrossRef] [PubMed]

4. Wang, H.; Jia, G. Satellite-based monitoring of decadal soil salinization and climate effects inasemi-arid region of China. Adv. Atmos. Sci. 2012, 29, 1089-1099. [CrossRef]

5. Allbed, A.; Kumar, L. Soil salinity mapping and monitoring in arid and semi-arid regions using remote sensing technology: A review. Adv. Remote Sens. 2013, 2, 13. [CrossRef]

6. Yang, C.; Lv, D.; Jiang, S.; Lin, H.; Sun, J.; Li, K.; Sun, J. Soil salinity regulation of soil microbial carbon metabolic function in the Yellow River Delta, China. Sci. Total. Environ. 2021, 790. [CrossRef] [PubMed]

7. Zhang, H.; Li, Y.; Deng, H.W.; Li, H.; Zhang, X.X.; Zhao, L.; Xie, J. Soil salinization classification in Manas river basin of Xinjiang based on remote sensing images. J. Northwest A F Univ. Nat. Sci. Ed. 2013, 41, 153-158.

8. Sahab, S.; Suhani, I.; Srivastava, V.; Chauhan, P.S.; Singh, R.P.; Prasad, V. Potential risk assessment of soil salinity to agroecosystem sustainability: Current status and management strategies. Sci. Total Environ. 2021, 764. [CrossRef]

9. Ivushkin, K.; Bartholomeus, H.; Bregt, A.K.; Pulatov, A.; Kempen, B.; de Sousa, L. Global mapping of soil salinity change. Remote Sens. Environ. 2019, 231. [CrossRef]

10. Rao, B.R.M.; Sharma, R.C.; Ravi Sankar, T.; Das, S.N.; Dwivedi, R.S.; Thammappa, S.S.; Venkataratnam, L. Spectral behaviour of salt-affected soils. Int. J. Remote Sens. 1995, 16, 2125-2136. [CrossRef]

11. Wang, P.; Wang, L.; Leung, H.; Zhang, G. Super-Resolution Mapping Based on Spatial-Spectral Correlation for Spectral Imagery. IEEE Trans. Geosci. Remote Sens. 2020, 59, 2256-2268. [CrossRef]

12. Brunner, P.; Li, H.; Kinzelbach, W.; Li, W. Generating soil electrical conductivity maps at regional level by integrating measurements on the ground and remote sensing data. Int. J. Remote Sens. 2007, 28, 3341-3361. [CrossRef]

13. Madani, A.A. Soil Salinity Detection and Monitoring Using Landsat Data: A Case Study from Siwa Oasis, Egypt. GIScience Remote Sens. 2005, 42, 171-181. [CrossRef]

14. Azabdaftari, A.; Sunar, F. Soil salinity mapping using multitemporal landsat data. The international archives of the photogrammetry. Int. Arch. Photogramm. Remote Sens. Spat. Inf. Sci. 2016, 41, B7. [CrossRef]

15. Hoa, P.V.; Giang, N.V.; Binh, N.A.; Hai, L.V.H.; Pham, T.D.; Hasanlou, M.; Bui, D.T. Soil salinity mapping using SAR sentinel-1 data and advanced machine learning algorithms: A case study at ben tre province of the Mekong river delta (Vietnam). Remote Sens. 2019, 11, 128. [CrossRef] 
16. Farifteh, J.; Van der Meer, F.; Atzberger, C.; Carranza, E.J.M. Quantitative analysis of salt-affected soil reflectance spectra: A comparison of two adaptive methods (PLSR and ANN). Remote Sens. Environ. 2007, 110, 59-78. [CrossRef]

17. Morgan, R.S.; El-Hady, M.A.; Rahim, I.S. Soil salinity mapping utilizing sentinel-2 and neural networks. Indian J. Agric. Res. 2018, 52, 524-529. [CrossRef]

18. Wang, F.; Ding, J.L.; Wu, M.C. Remote sensing monitoring models of soil salinization based on NDVI-SI feature space. Trans. China Soc. Agric. Eng. 2010, 26, 168-173. [CrossRef]

19. Ha, X.P.; Ding, J.L.; Tiyip, T.; Luo, J.Y.; Zhang, F. SI-Albedo space-based extraction of salinization information in Arid area. Acta Pedol. Sin. 2009, 46, 381-390.

20. Ding, J.L.; Qu, J.; Sun, Y.M.; Zhang, Y.F. The retrieval model of soil salinization information in arid region based on MSAVI-WI feature space:A case study of the delta oasis in Weigan-Kuqa watershed. Geogr. Res. 2013, 32, 223-232. [CrossRef]

21. Liu, Y.; Qian, J.; Yue, H. Comparison and evaluation of different dryness indices based on vegetation indices-land surface temperature/albedo feature space. Adv. Space Res. 2021, 68, 2791-2803. [CrossRef]

22. Guo, B.; Yang, F.; Fan, Y.W.; Han, B.M.; Chen, S.T.; Yang, W.N. Dynamic monitoring of soil salinization in yellow river delta utilizing MSAVI-SI feature space models with Landsat images. Environ. Earth Sci. 2019, 78, 1-10. [CrossRef]

23. Zhang, T.Y.; Wang, L.; Zeng, P.; Wang, T.; Geng, Y.; Wang, H. Soil Salinization in the Irrigated Area of the Manas River Basin Based on MSAVI-SI Feature Space. Arid Zone Res. 2016, 33, 499-505. [CrossRef]

24. Li, P.; Chen, S.; Xu, C.; Du, J.; Wu, D. Sedimentary characteristics and spatial differentiations of the sedimentary facies in the Yellow River sub-delta lobes during the different historical periods. Reg. Stud. Mar. Sci. 2021, 47. [CrossRef]

25. Li, Q.; Yang, P.N.; Peng, L.; Zhou, L.; Yusufujiang, R.; Wang, H.P.; Zhang, W.T. Study of the variation trend of evapotranspiration in the Yanqi Basin based on MOD16 data. Arid Zone Res. 2021, 38, 351-358.

26. Zhang, W.T.; Wu, H.Q.; Gu, H.B.; Feng, G.-L.; Wang, Z.; Sheng, J.D. Variability of Soil Salinity at Multiple Spatio-Temporal Scales and the Related Driving Factors in the Oasis Areas of Xinjiang, China. Pedosphere 2014, 24, 753-762. [CrossRef]

27. Peng, J.; Biswas, A.; Jiang, Q.; Zhao, R.; Hu, J.; Hu, B.; Shi, Z. Estimating soil salinity from remote sensing and terrain data in southern Xinjiang Province, China. Geoderma 2019, 337, 1309-1319. [CrossRef]

28. Yang, X.; Wu, J.J.; Yan, F.; Zhang, J. Assessment of regional soil moisture status based on characteristics of surface temperature/vegetation index space. Acta Ecol. Sin. 2009, 29, 1205-1216. [CrossRef]

29. Feng, J.; Ding, J.L.; Wei, W.Y. The study of Soil Salinization in Weigan and Kuqa Rivers oasis based on Albedo-MSAVI feature space. China Rural. Water Hydropower 2018, 2, 147-152.

30. Wu, Z.P.; Wang, M.X.; Zhao, X. A study on desertification based on desertification difference index in Jinghe watershed. Bull. Soil Water Conserv. 2014, 34, 188-192. [CrossRef]

31. Zhang, S.M.; Zhao, G.X.; Wang, Z.R.; Xiao, Y.; Lang, K. Remote sensing inversion and dynamic monitoring of soil salt in coastal saline area. J. Agric. Resour. Environ. 2018, 35, 349-358.

32. Liu, G.; Li, J.; Zhang, X.; Wang, X.; Lv, Z.; Yang, J.; Shao, H.; Yu, S. GIS-mapping spatial distribution of soil salinity for Eco-restoring the Yellow River Delta in combination with Electromagnetic Induction. Ecol. Eng. 2016, 94, 306-314. [CrossRef]

33. Lu, R.K. Analytical Methods of Soil Agricultural Chemistry; China Agricultural Science Press: Beijing, China, 2000; ISBN 7-80119-925-1.

34. Department of Agriculture and Rural Affairs of Xinjiang. Soil of Xinjiang; Science Press: Beijing, China, 1996 ; ISBN 7030051998.

35. Bian, L.; Wang, J.; Liu, J.; Han, B. Spatiotemporal Changes of Soil Salinization in the Yellow River Delta of China from 2015 to 2019. Sustainability 2021, 13, 822. [CrossRef]

36. Khan, N.; Sato, Y. Monitoring hydro-salinity status and its impact in irrigated semi-arid areas using IRS-1B LISS-II data. Asian J. Geoinform. 2001, 1, 63-73.

37. Wang, N.N.; Qi, W.; Wang, D.; Qin, T.T.; Lu, C. Spatial variability of soil nutrients and salinity in coastal saline-alkali land based on belt transect method. J. Appl. Ecol. 2012, 23, 1527-1532.

38. Wang, Z.R.; Zhao, G.X.; Gao, M.X.; Jiang, S.Q.; Chang, C.Y.; Jia, J.C. Characteristics of soil water and salt spatial variations in the spring season in typical yellow river delta areas of Kenli county. China J. Agric. Resour. Env. 2015, 32, 154-161. [CrossRef]

39. Wang, S.X.; Wu, B.; Yang, P.N.; Li, X.; Dong, X.G. Determination of the Ecological Groundwater Depth Considering Ecological Integrity over Oasis Irrigation Areas in the Yanqi Basin. Resour. Sci. 2011, 33, 422-430.

40. Wang, W.W.; Mamattursun, E.; Atiyagul, R.; Anwar, M. Spatial variability and distribution pattern of soil salinity factors in topsoil of farmland in Yanqi Basin, Xinjiang. Agric. Res. Arid Areas 2019, 37, 195-201. [CrossRef]

41. Jiang, H.; Yusufujiang, R.; Reyilai, K.; Adilai, W. Evaluation and Analysis of Soil Salinization in the Arid Zones based on Neural Network Model. J. Geo-Inf. Sci. 2017, 19, 983-993. [CrossRef]

42. Wang, B.; Ma, X.W.; Shan, N.N.; Yang, T.; Liu, H.; Niu, X. The selection and application of saline alkali soil amendment in Xinjiang. J. Arid Land Resour. Environ. 2014, 28, 111-115.

43. Wang, H.J.; Shi, J.C.; Zhang, H.L.; Sheng, J.D.; Ma, X.W.; Wu, H.Q.; Ren, S.T.; Zuo, Q.; Li, B.G. Soil salinity dynamic change and desalting effect under different improvement measures in severe salinity soil in Xinjiang. Trans. Chin. Soc. Agric. Eng. 2014, 30, 102-111. [CrossRef] 